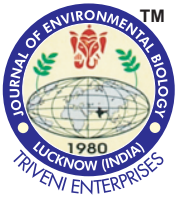

\title{
Determining the genetic relationships between cultivated type olives using ISSR and morphological markers
}

\section{Authors Info}

E.D. Yegenoglu* ${ }^{1 *}$ M. Sesli and Y. Gevrekci

'Department of Plant and Animal Production, Alasehir Vocational School, Manisa Celal Bayar University, Alasehir, Manisa, 45400, Turkey

${ }^{2}$ Department of Tobacco Breeding, School of Tobacco Expertise, Manisa Celal Bayar University, Akhisar, Manisa, 45210, Turkey ${ }^{3}$ Department of Animal Science, Unit of Biometry-Genetics, Bornova, Agriculture Faculty, Ege University, Izmir, 35100, Turkey

*Corresponding Author Email : yegenoglu75@hotmail.com

Key words

Euclidean distance,

ISSR markers,

Morphological characters,

Olives,

UPGMA

\section{Publication Info}

Paper received : 08.08.2016

Revised received : 25.06.2017

Accepted : 28.06.2017

\section{Abstract}

Aim: The study aimed to compare morphological characters and Inter-simple sequence repeat (ISSR) data based trees, and examine the genetic relations in ten olive varieties among cultivated type olives grown commonly in different regions of Turkey.

Methodology: Ten olive varieties were evaluated with some morphologic markers and ISSR marker. All analyses were conducted with Numerical Taxonomy System (NTSYS). The cluster analysis was performed with unweighted pair group method with arithmetic average (UPGMA) clustering algorithm.

Results: The results showed that there was a moderate correlation between pairwise distances estimated from ISSR data and distances from morphological characters (0.511). The Euclidean Distance matrix represented that the lowest value was between Tavsan Yuregi and Cilli (1.62), while the highest value was between Manzanilla and Cekiste (7.91). According to Jaccard coefficient, the samples closest to each other were (Memecik and Gemlik); and the samples farthest to each other were (Halhali and Manzanilla).

Interpretation: Determining the genetic relations in agriculturally economic plants is valuable in terms of protecting the gene sources, determining the homonyms and synonyms, and developing breeding programs. Morphological and molecular markers may be used in the identification of genetic variability. Mutually complementary information can be obtained by using morphological and molecular markers together.

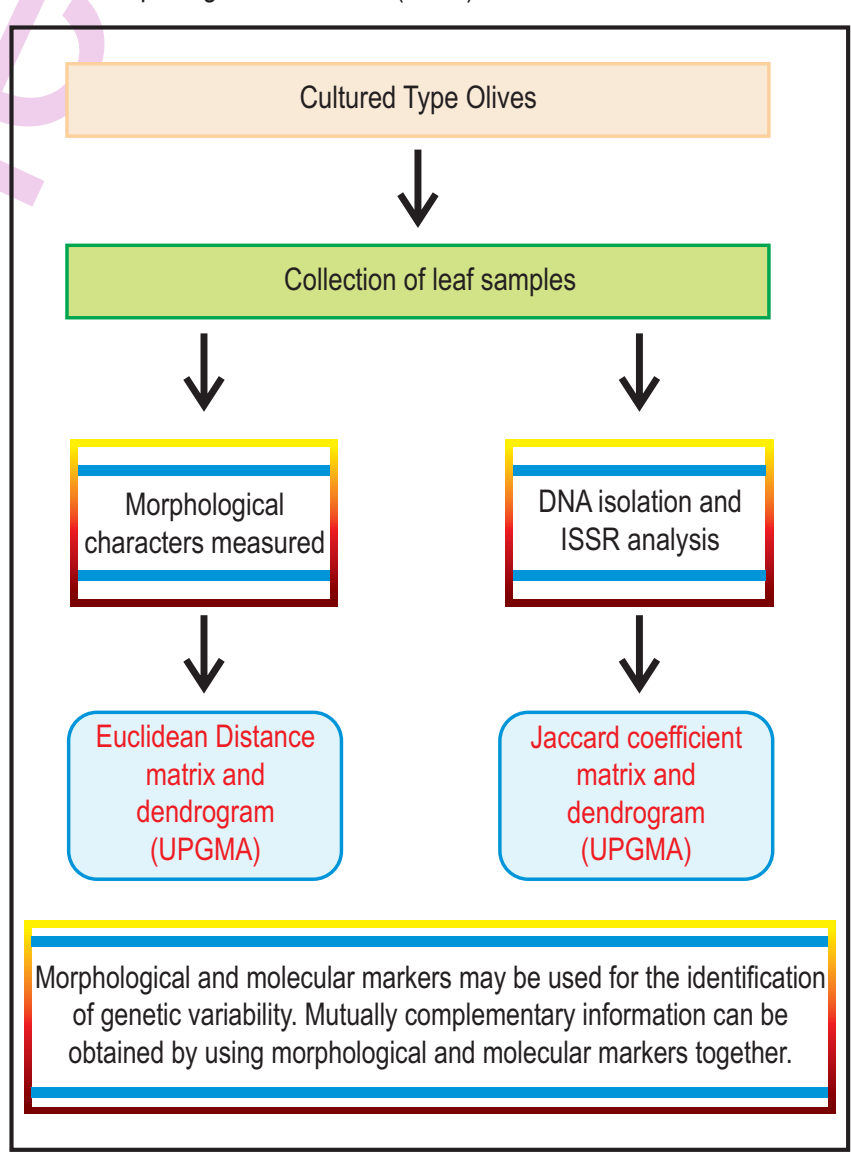




\section{Introduction}

Olive, native of Anatolia, is an important agricultural subtropical climate plant grown in the countries of Mediterranean basin. It is consumed as both table olives and oil, and Turkey is one of the countries where this plant is grown. Determining the genetic structure of plants having an economic significance such as olives are important in terms of cultivation and breeding studies. Determination of genetic similarities and differences in both wild and cultivated forms is valuable in terms of identifying the genetic variability (Parlak and Coşkun, 2007). Understanding the genetic structure of a plant is also important in protecting gene sources and developing breeding programs (Rana et al., 2005). Molecular and morphologic markers are used in determining the genetic variability, estimating the genetic relationships.

Morphological characteristics such as leaf width, leaf length, and stem length may be used in the identification of variability. Morphological characterization may also be used in finding the correlation among properties of agricultural importance and distinguishing the homonyms and synonyms (Karuri etal., 2010).

Molecular markers are frequently used for searching the genetic differences in plants at DNA level (Semagn et al., 2006). ISSR markers, which are produced through ISSR technique based on the multiplication of DNA parts between two simple sequence repetition regions reversely positioned and at reproducible distance through PCR, are used for determining the genetic differences of olive types and the variation in olive clones (Zietkiewicz et al., 1994; Gomes et al., 2008; Martins-Lopes et al., 2007; Leva and Petrucelli, 2012). Morphologic characters were used in cladistic analysis in olives (Al-Ruqaie, 2016), and in genetic characterization of molecular markers and morphologic characters together (Milotic et al., 2005; Zaher et al., 2011).

The aspects with phenotypes developed are genetics and environment. Therefore, the environmental conditions and the relations between environment and genetics affect the phenotypic expression. Environmental conditions may be effective on the morphologic and agronomic characters of a plant (Delgado et al., 2008; Beland, 2016).

Whereas, the molecular markers are not affected by environmental conditions and genetic differences and polymorphisims may be determined on DNA level without the need of a prior information about growth, differentiation, development or status of cells of plant tissues (Sergio and Gianni, 2005; Lenka et al., 2015). Morphologic markers and DNA markers are used in finding the genetic variability, genetic distances and closeness in plants together (Rana et al., 2005; Vieira et al., 2007). While the morphologic data provide significant data in profiling the varieties, evaluating them together is a method that can be useful for determining the genetic structure of species and interrelation of cultivars

The present study aimed to examine the genetic relations using morphologic and molecular markers on ten olive varieties among the cultivated type olives grown commonly in different regions of Turkey.

\section{Materials and Methods}

Memecik, Uslu, Domat, Cilli, Gemlik, Cekiste, TavsanYüregi, Halhali and Manzanilla).For each olive type, three trees selected and ten samples were collected from each tree (3x10) and total thirty samples were examined for each olive type. As morphologic characters, the leaf length, leaf width, leaf width to length ratio, stem length, stem thickness, fruit size, fruit width, seed size, seed size to width ratio were selected and measured.

DNA isolation and spectrophotometry: DNA was isolated from fresh leaves according to Doyle and Doyle $(1987,1990)$ method with modifications. Plant tissues ground with liquid nitrogen in mortar, and immediately transferred to $1.5 \mathrm{ml}$ Eppendorf tubes, $700 \mu$ preheated CTAB extraction buffer ( $2 \%$ CTAB, $20 \mathrm{mM}$ EDTA, 1.4 M NaCl, 100 mMTris-HCl pH 8.0, 2\% DTT) added and mixed several times by gentle inversions. Samples were incubated for $30 \mathrm{~min}$ in $65^{\circ} \mathrm{C}$, mixing by inversions in every $5 \mathrm{~min}$. Samples were cooled down and added $700 \mu \mathrm{l}$ of cold chloroform:isoamyl alcohol (24:1). Tubes were spun for $10 \mathrm{~min}$ at $10.000 \mathrm{rpm}$ per min at $+4{ }^{\circ} \mathrm{C}$ centrifuge. Supernatants were poured into new tubes; $600 \mu$ l of cold chloroform isoamyl alcohol (24:1) was added, mixing by gentle inversions for $5 \mathrm{~min}$. Samples were spun for $10 \mathrm{~min}$ at $10.000 \mathrm{rpm}$ per min in a refrigerated centrifuge and supernatants were transferred to fresh tubes including $10 \mathrm{M}$ ammonium acetate and $3 \mathrm{M} \mathrm{Na}$ - acetate; $500 \mu \mathrm{l}$ cold isopropanol added and mixed by shaking gently for DNA precipitation. Precipitated DNA was removed and washed with $70 \%$ ethanol. DNA's were then dried and re-suspended in EDTA.

In the spectrophotometric analysis, the optical density of each sample of DNA was determined at 260 and $280 \mathrm{~nm}$ (Gamma Helios Spectrophotometer). Optical density ratios were evaluated and only good-quality DNA samples were used in polymerase chain reaction (Wu et al., 2004).

ISSR analysis : Five pre-selected ISSR primers (University of British Columbia-UBC primers), UBC-826 (ACA CAC ACA CAC ACA CC), UBC-855 (ACA CAC ACA CAC ACA CYT), UBC-817 (CAC ACA CAC ACA CAC AA), UBC-818 (CAC ACA CAC ACA CAC AG) , and UBC-849 (GTG TGT GTG TGT GTG TYA) were used for PCR amplification. ISSR amplification reactions were carried out in $25 \mu$ l volume containing $25 \mathrm{ng}$ DNA, primer $4 \mu \mathrm{l}$, PCR buffer $2.5 \mu \mathrm{l}$, dNTP stock $2 \mu \mathrm{l}$, Taq NA polymerase $0.5 \mu \mathrm{l}$. PCR cycles were taken from Martins-Lopes et al. (2007). The amplification reactions of ISSR were carried out following these steps: Initial denaturation $94^{\circ} \mathrm{C} 5 \mathrm{~min}$; followed by 45 cycles of 94 
${ }^{\circ} \mathrm{C} 30 \mathrm{sec}, 52^{\circ} \mathrm{C} 45 \mathrm{sec} ., 72^{\circ} \mathrm{C} 2 \mathrm{~min}$, and final extension of $72^{\circ} \mathrm{C}$ $5 \mathrm{~min}$.

Gel electrophoresis: Agarose-gel-electrophoresis (1.2\%) was performed for separating DNA fragments. Following the agarosegel-electrophoresis, the gels were dyed with ethidium bromide. The bands provided by each ISSR primers were evaluated as an independent locus each and a data matrix was developed to include for the presence and 0 for the absence of bands.

Data analysis : All the analyses were performed through NTSYS 2.01 program (Rohlf, 1997). For morphological characters, the raw data were converted to rectangular matrix, and standardized with STAND option in NTSYS 2.01. Then, compute pair wise population distance matrix was generated by using EUCLIDEAN, and MANHATTAN distances (SIMINT), and cluster analysis was performed with unweighted pair group method with arithmetic average (UPGMA) clustering algorithm (SAHN).

To determine the genetic relationships between olive cultivars, the binary data obtained from ISSR analysis were used for cluster analysis and produced dendrograms. Jaccard and Simple Matching similarity coefficient was used for establishing the genetic matrix (SIMQUAL, SAHN) (Sokal and Michener, 1958).

The matrices from ISSR binary data and morphological characters were compared by MXCOMP procedure of NTSYS 2.01. The co-phenetic correlation between the distance matrix and the distance cluster for ISSR and morphological data sets were estimated by COPH option in NTSYS 2.01. The distance and coefficient with highest correlation were used for evaluation.

\section{Results and Discussion}

The Mantel test results showed moderate correlation between pairwise distances estimated from ISSR data and distances from morphological characters (Table 1). The highest correlation was found between Euclidean Distance and Jaccard Coefficient $(r=0.511$, normalized Mantel statistic $Z, t=3.49$, Prob. random $Z<$ obs. $Z: p=0.99$ ).

Zhou et al. (2013) found high goodness of fit for Mantel Test when they classified Evergreen Azalea (Ericacea) cultivars in China with morphological characters. We also determined well goodness of fit for each of molecular and morphological matrices. While Karuri et al. (2010) showed very low correlations between

Table 1 : Mantel test results demonstrate correlations between molecular and morphological matrices

\begin{tabular}{lll}
\hline & $\begin{array}{l}\text { Jaccard } \\
\text { coefficient }\end{array}$ & $\begin{array}{l}\text { Simple matching } \\
\text { coefficient }\end{array}$ \\
\hline Euclidean distance & 0.5115 & 0.2499 \\
Manhattan distance & 0.5025 & 0.2235 \\
\hline
\end{tabular}

morphological and molecular dendrograms $(r=-0.05)$ in sweet potato genotypes evaluating with SSR and morphological markers Vieira et al. (2007) found high correlation ( $r=0.97)$ for combined molecular and morphological matrices for genetic distances in wheat (Triticum aestivum L.) estimating by AFLP and morphological markers.

Vieira et al. (2007) also indicated that Máric et al. (2004) obtained low correlation with RAPD markers and wheat morphological characters. Rana et al. (2005) reported nonsignificant correlation between the AFLP'S pair-wise distances and the average taxonomic distances in upland cotton (Gossypium hirsutum L.) breeding lines in India, using AFLP and morphological markers for estimating genetic diversity. The studies showed the number of morphological characters, the selected molecular marker and genomic structure of the plant affect the analysis.

For the dendrogram estimated from Euclidean Distance, and Jaccard Coefficient, cophenetic correlations between the dendrograms and the matrices revealed a good degree of fit $(r=$ 0.816, Prob. random $Z$ < obs. $Z$ : $p=0.998 ; r=0.901$, Prob. random $Z<$ obs. $Z: p=1.000$ ). Table 2 and 3 shows the matrices from Euclidean Distance and Jaccard Coefficient.

The Euclidean Distance matrix represented that the lowest value was between Tavsan Yuregi and Cilli (1.62), while the highest value was between Manzanilla and Cekiste (7.91). As shown in Fig. 1, the UPGMA dendrogram based on Euclidean Distance revealed that there were two main clusters, and separate lines of Manzanilla in the dendrogram. The Cluster 1 included Edremit, Memecik, TavsanYuregi, Cilli, Uslu, Domat and Cekiste olives. One of the sub-clusters represented TavsanYuregi, Cilli and Memecik when the lowest distance determined between Tavsan Yuregi and Cilli olives. The cluster 2 was formed by Gemlik and Halhali olives as their distance was 3.99. Manzanilla olive formed a separate cluster.

The genetic distance values from Jaccard Coefficient was found between 0.04 (Memecik and Gemlik) and 0.30 (Halhali and Manzanilla). Thus, based on the genetic distance values; the samples closest to each other were (Memecik and Gemlik); and based on the genetic distance values, the samples farthest to each other were (Halhali and Manzanilla). Determining the samples closest to each other as (Memecik and Gemlik) based on the genetic distance values shows that although Memecik variety was partially self-productive, Gemlik variety may be used as parent for the Memecik variety. Determining the samples farthest to each other as (Halhali and Manzanilla) based on the genetic distance values, Halhali is Turkey's local variety originating in Mardin province; however, Manzanilla is a foreign variety originating from Cordoba, Spain and it has adapted to Turkey in time. This explains the reason why Halhali and Manzanilla are distant to each other genetically (Canözer and Gökçe, 1991). 
Table 2: Euclidean Distance matrix of olive cultivars obtained from morphological characters

\begin{tabular}{|c|c|c|c|c|c|c|c|c|c|c|}
\hline & Edremit & Memecik & Uslu & Domat & Cilli & Gemlik & $\begin{array}{l}\text { Tavsan } \\
\text { yüregi }\end{array}$ & Halhali & Manzanilla & Cekiste \\
\hline Edremit & $* * *$ & & & & & & & & & \\
\hline Memecik & 3.86 & $* * *$ & & & & & & & & \\
\hline Uslu & 4.17 & 2.26 & $* * *$ & & & & & & & \\
\hline Domat & 3.72 & 4.09 & 3.94 & $* * *$ & & & & & & \\
\hline Cilli & 3.68 & 2.81 & 3.21 & 2.65 & $* * *$ & & & & & \\
\hline Gemlik & 4.35 & 2.94 & 3.75 & 5.52 & 3.78 & $* * *$ & & & & \\
\hline TavsanYüregi & 3.16 & 1.68 & 2.44 & 2.74 & 1.62 & 3.28 & $* * *$ & & & \\
\hline Halhali & 4.51 & 4.59 & 3.88 & 5.67 & 4.78 & 3.99 & 4.25 & $* * *$ & & \\
\hline Manzanilla & 4.61 & 6.05 & 6.29 & 6.07 & 5.17 & 5.38 & 5.68 & 7.28 & $* * *$ & \\
\hline Cekiste & 5.65 & 3.04 & 4.39 & 4.19 & 3.55 & 5.18 & 2.92 & 6.47 & 7.91 & $* * *$ \\
\hline
\end{tabular}

Table 3 : Jaccard Coefficient matrix of olive cultivars obtained from ISSR binary data

\begin{tabular}{|c|c|c|c|c|c|c|c|c|c|c|}
\hline & Edremit & Memecik & Uslu & Domat & Cilli & Gemlik & $\begin{array}{l}\text { Tavsan } \\
\text { yüregi }\end{array}$ & Halhali & Manzanilla & Cekiste \\
\hline Edremit & $* * *$ & & & & & & & & & \\
\hline Memecik & 0.00 & $* * *$ & & & & & & & & \\
\hline Uslu & 0.00 & 0.00 & $* * *$ & & & & & & & \\
\hline Domat & 0.17 & 0.00 & 0.11 & $* * *$ & & & & & & \\
\hline Cilli & 0.06 & 0.00 & 0.00 & 0.07 & $* * *$ & & & & & \\
\hline Gemlik & 0.00 & 0.04 & 0.06 & 0.00 & 0.09 & $* * *$ & & & & \\
\hline TavsanYüregi & 0.12 & 0.05 & 0.00 & 0.07 & 0.11 & 0.00 & $* * *$ & & & \\
\hline Halhali & 0.00 & 0.07 & 0.00 & 0.00 & 0.00 & 0.06 & 0.07 & $* * *$ & & \\
\hline Manzanilla & 0.00 & 0.00 & 0.00 & 0.00 & 0.06 & 0.00 & 0.06 & 0.30 & $* * *$ & \\
\hline Cekiste & 0.00 & 0.00 & 0.09 & 0.00 & 0.00 & 0.11 & 0.06 & 0.00 & 0.00 & $* * *$ \\
\hline
\end{tabular}

Fig. 2 shows the Jaccard UPGMA dendrogram. Two main clusters were obtained from Jaccard UPGMA. The cluster 1 was divided into two sub-clusters formed by Edremit and Domat, Cilli and Gemlik, Uslu, Cekiste and Manzanilla. The cluster 2 grouped Memecik, TavsanYuregi and Halhali olives.

The dendrograms from morphological characters and molecular markers showed different clustering pattern. While Manzanilla formed a separate cluster in Euclidean Distance UPGMA, it grouped with Cekiste in Jaccard UPGMA. In morphological based dendrogram, Cilli and TavsanYuregi olives were in the same cluster, however, molecular marker based dendrogram, Tavsan Yuregi and Halhali were placed in the same cluster.

Zhou et al. (2013) evaluated Azalea plant with morphological markers via numerical taxonomy; they revealed that UPGMA dendrogram was consistent with the traditional classification system. Al-Ruqaie et al. (2016) indicated that morphological characters were used successfully in detecting relationships in many species including olives. They reported that the morphological analysis can be used to distinguish olive varieties unless the varieties were morphologically similar. Karuri et al. (2010) also found that the genotypes clustered in SSR analysis of sweet potato genotypes were placed in different groups in morphological characters based dendrogram. Several other studies have indicated low or no correlation between pairwise distances and taxonomic distances from morphological and molecular markers as Rana et al. (2005) stated.

Vieira et al. (2007) obtained high correlation between combined AFLP marker and morphological data. In this study, a moderate correlation $(r=0.5115)$ was found between ISSR and morphological distances. Our results can be explained by highly polymorphic nature of ISSR markers. ISSR markers can also reveal intravarietal diversity in clones, since it can amplify the hypervariable non-coding regions (Martins-Lopes et al., 2009). Only five ISSR primers were analyzed and the studies reported that olive tree had polymorphic genomic structure. Several factors may affect the analysis such as breeding status, numbers and types of markers, genomic structure of the plant and the number of morphological characters.

Rana et al. (2005) reported that genotypes giving morphologically similar results should not be genetically similar, but it would be different for closely associated commercial breeds. In addition, different parents may be pollinator for some olive varieties. Morphological and molecular markers presented 


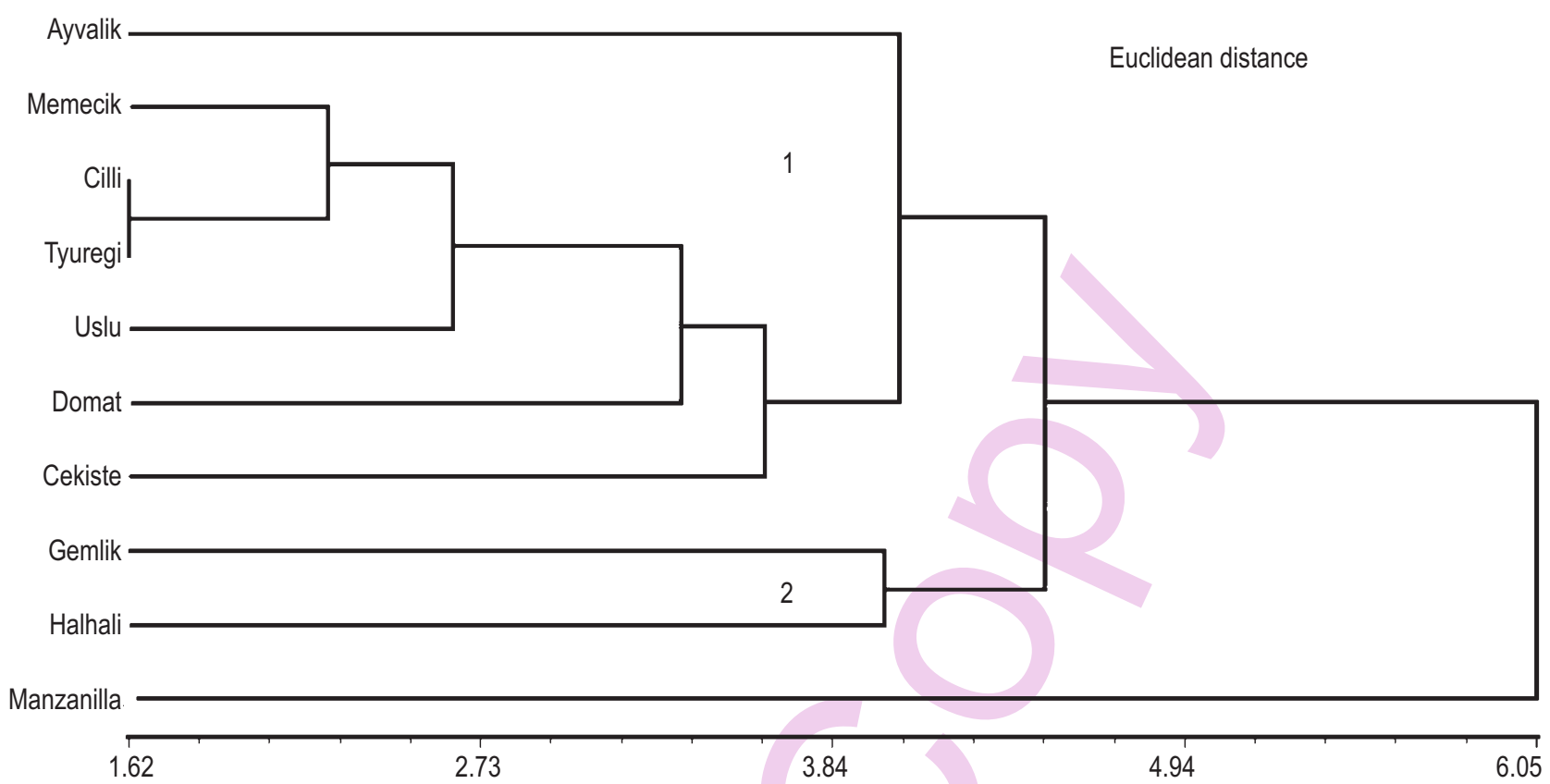

Fig. 1 : Euclidean Distance (UPGMA) dendrogram of olive cultivars

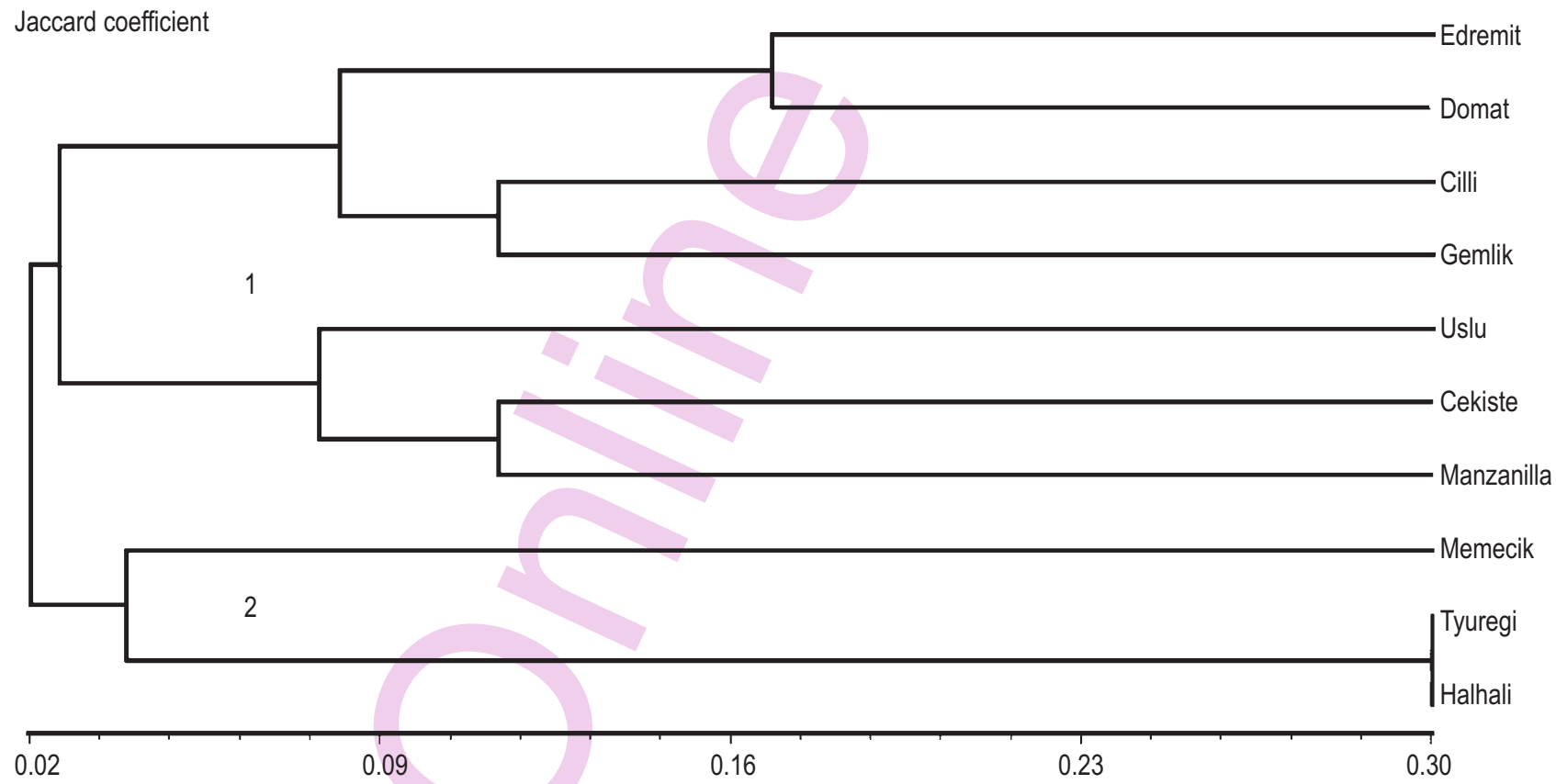

Fig. 2 : Jaccard Coefficient (UPGMA) dendrogram of olive cultivars

polymorphic structure of olives. Combined using of morphological and molecular markers was useful for evaluating genetic background of olive, and can also give more detailed description of varieties. ISSR markers could successfully detect genetic diversity. Further, studies with more primers, morphological characters and more varieties can be useful for determining the characterization of olive varieties.

\section{Acknowledgment}

This study has been supported by the Scientific Research Projects Coordination Unit of Celal Bayar University, Manisa, Turkey. 


\section{References}

Al-Ruqaie, I., N.S. Al-Khalifah and A.E. Shanavaskhan: Morphological cladistic analysis of eight popular olive (Olea europaea L.) cultivars grown in Saudi Arabia using Numerical Taxonomic System for personal computer to detect phyletic relationship and their proximate fruitcomposition. Sau. J. Biol. Sci., 23, 115-121 (2016).

Béland, C.: Effects of genetic and environmental variation on the morphology of Pimelodella chagresi, a neotropical catfish Species.

https://www.mcgill.ca/pfss/files/pfss/Catfish_Report.pdf. (2016)

Canözer, Ö. and H. Gökçe: Standard olive varieties Catalogue. Ministry of Agriculture and Rural Affairs, Republic of Turkey, Occupational Publications Series. No: 334 (16), (1991).

Delgado, I., C. Andrés and F. Munoz: Effect of the environmental conditions on diff erent morphological and agronomical characteristics of sainfoin. Cahiers Options Méditerranéennes, 79 , 199-202 (2008).

Doyle, J.J. and J.L. Doyle: A rapid DNA isolation procedure for small quantities of fresh leaf tissue. Phytochem. Bull., 19, 11-15(1987).

Doyle, J.J. and J.L. Doyle: Isolation of plant DNA from fresh tissue. Focus., 12, 13-15(1990).

Gomes, S., P. Martins-Lopes, J. Lima-Brito, J. Meirinhos, J. Lopes, A. Martins and $\mathrm{H}$. Guedes-Pinto: Evidence of clonal variation in olive 'Verdeal-Transmontana' cultivar using RAPD, ISSR and SSR markers. J. Horticul. Sci. Biotechnol., 83, 395-400 (2008).

Karuri, H.W., E.M. Ateka, R. Amata, A.B. Nyende, A.W.T. Muigai, E. Mwasame and S.T. Gichuki: Evaluating diversity among Kenyan sweet potato genotypes using morphological and SSR markers. Int. J. Agric. Biol., 12, 33-38 (2010).

Lenka, D., S.K. Tripathy, R. Kumar, M. Behera and R. Ranja: Assessment of genetic diversity in quality protein maize (QPM) inbreds using ISSR markers. J. Env. Biol., 36, 985-992 (2015).

Leva, A.R. and R. Petruccelli: Monitoring of cultivar identity in micropropagated olive plants using RAPD and ISSR markers. Biologia Plantarum, 56, 373-376 (2012).

Máric, S., S. Laríc, J. Artincic, I. Pejíc and V. Kozumplink: Genetic diversity of hexaploid wheat cultivars estimated by RAPD markers, morphological traits and coefficients of parentage. Plant. Breed., 123, 366-369 (2004).

Martins-Lopes, P., J.S. Lima-Brito Gomes, J. Meirinhos, L. Santos and H. Guedes-Pinto: RAPD and ISSR molecular markers in Olea europaea L. Genetic variability and molecular cultivar identification. Genet. Res. Crop. Evol., 54, 117-128 (2007).

Martins-Lopes, P., S. Gomes, J. Lima-Brito, J. Lopes and H. Guedes-
Pinto: Assessment of clonal genetic variability in Olea europaea $L$. 'Cobrançosa' by molecular markers. Sci. Hort., 123, 82-89 (2009).

Milotic, A., E. Setic, D. Persuric, D. Poljuha, B. Sladonja and K. Brscic: Identification and characterization of autochthonous olive varieties in Istria (Croatia). Ann. Ser. His. Nat., 14, 251-256 (2005).

Parlak, S., and F. Coşkun: Molecular systematic analysis of some olive cultivars (Olea europaea L.) grown in Marmara region. [M.Sc. Thesis]. Balikesir University, Ins. of Natural and Applied Sciences. Marmara Bölgesinde Yetiştirilen Bazı Zeytin Kültivarlarının Moleküler Sistematik Analizi. [Y. LisansTezi]. Balıkesir Üniversitesi Fen Bilimleri Enstitüsü. (2007).

Rana, M.K., V.P. Singh and K.V. Bhat: Assessment of genetic diversity in upland cotton (Gossypium hirsutum L.) breeding lines by using amplified fragment length polymorphism (AFLP) markers and morphological characteristics. Genet. Res. Crop. Evol., 52, 989-997 (2005).

Rohlf, F.J.: NTSYS-Pc. Numerical taxonomy and multivariate analysis system version 2.01. Exeter Software. New York. (1997).

Semagn, K., A. Bjornstad and M.N. Ndjiondjop:An overview of molecular marker methods for plants. African. J. Biotechnol., 5, 2540-2568 (2006).

Sergio L. and B. Gianni: Molecular markers based analysis for crop germplasm preservation. In: The role of biotechnology for the characterisation and conservation of crop, forestry, animal and fishery genetic resources. International workshop, FAO, 5-7 March, 2005. Villa Gualino, Turin, Italy. (2005).

Sokal, R.R. and C.D. Michener: A statistical method for evaluating systematic relationships. Univ. Kans. Sci. Bull., 38, 1409-1438 (1958).

Wu, S., G. Collins and M.A. Sedgley:. Molecular linkage map of olive (Olea europea L.) based on RAPD, microsatellites and SCAR markers. Genome, 47, 26-35 (2004).

Vieira, E.A., F.I.F. Carvalho, I. Bertan and M.M. Kopp: Association between genetic distances in wheat (Triticum aestivum L.) as estimated by AFLP and morphological markers. Genet. Mol. Biol., 30, 392-399 (2007).

Zaher, H., B. Boulouha, M. Baaziz, L. Sikaoui, F. Gaboun and S.M. Udupa: Morphological and genetic diversity in olive (Olea europaea subsp. europaea L.) clones and varieties. Plant Omics J. 4,370-376 (2011).

Zhou, H., J. Liao, Y.P. Xiaand Y.W. Teng. Morphological characteristics for classifying ever greenazalea (Ericaceae) cultivars in China using numerical taxonomy. Pak. J. Bot., 45, 593-598 (2013).

Zietkiewicz, E., A. Rafalski and D. Labuda: Genome fingerprinting by simple sequence repeats (SSR)-anchored PCR amplification. Genomics, 20, 176-183 (1994). 